\title{
COMMUNITY MANAGEMENT OF THE WATERFRONT: EXPLORING COMMUNITY SPACE AND ACTIVITY FOR ECONOMIC STABILITY IN TOMITSU, AMAKUSA CITY, JAPAN
}

\author{
OKOKO ANITA NYAPALA \\ Regional Environment Design Laboratory, Kumamoto University, Japan
}

\begin{abstract}
The community identity facets, respective use of resources and management of community assets are among key ingredients for sustainable local economic development and community economies. Likewise, the use and management of community spaces are at the heart of spatial practice as a concept of social space that determines sustainability or decline of local economic development and utility value of the said social space. The use and appreciation of the value of these spaces also depends on the size of user population and their capacities to increase spaces' economic viabilities. Japan and many countries in the developed world such as Germany, Sweden, Portugal and Spain have been facing a shrinking rural population for decades. A similar scenario of population decline presents itself in the Study area, Tomitsu. In October 2016, the New Urban Agenda recognized shrinking population as an emerging challenge to sustainable urban development that is associated with local development, and also proposed its management where appropriate. Many scholars have argued against the revitalization approach as a first course of action to manage city shrinkage because the approach does not necessarily require increased human population; nature and natural conditions can easily revitalize a region as a great centre of development. Proposed projects for such areas and scholars associated with this argument have however emphasized the importance of public space and activity in driving regeneration. This is why, given the challenges of population decline in the Tomitsu district, this study explored community space and community activity and the opportunities it provides as means to an end - economic stability, which is a vital first step to the regeneration of a shrinking region. The study aims to contribute some insight into the ongoing redevelopment process in Tomitsu through interactive participatory research in the community, and add to the academic knowledge in this field. The main aim of this study to is adapt and apply the theory accordingly.

Keywords: community space, local economic development, social space, community activity, local identity, shrinkage, regeneration, renovation.
\end{abstract}

\section{INTRODUCTION}

\subsection{Background}

Identity, use and management of community assets are vital for sustaining community economies [1]-[4]. Use and management comprise spatial practice as a concept of social space which can either lead to sustainability or decline. Biological reproduction (population growth) and socioeconomic production (economic growth) summate to social reproduction (sustained or continued community development) [5]. Therefore, population growth and economic growth complement each other for sustainable development to occur.

In October 2016, the New Urban Agenda recognized shrinking population as an emerging challenge to sustainable urban development and proposed its management where appropriate [6]. However, Japan and many countries in the developed world such as Germany, Sweden, Portugal and Spain have been facing shrinking rural population for decades [7], [8]. Considering Lefebvre's theory of social reproduction [5], population loss 
will upset the balance required for sustainable social reproduction. This is why these countries have attempted over time to develop policies and come up with projects to manage shrinkage.

A shrinking population is basically the onset of a ripple effect on the economy and community. When a population begins to shrink, without intervention it can only grow smaller. It leads to decrease in local production power and therefore decline in local economic development. This may have negative effects that contribute to decline in local purchasing power; decline in use of important local services (education, transport, housing); as well as a decline in the local government revenue and budget. The result effect is that it becomes uncomfortable for the remaining population to stay. This leaves mostly the aged population; when they age out this leaves deserted or ghost villages and towns; then the non-human kind of revitalization takes over. The REGEN analysis on depopulation explains these patterns [9]. The REGEN project by the LULEA Institute of Technology (LIT) in Sweden is a smart planning process that exists to determine which shrinking regions are worth saving and is purely an economic model based on the gaps created by the old type depopulation (Out-migration $>$ death surplus; and, Out-migration $>$ birth surplus). Simply, the small towns lose population to the larger towns and create a surplus in the smaller towns while leading to development gaps in the larger cities.

To elaborate further we may allude that a population is perceived to shrink when the current level is not enough to sustain facilities and activities that identify that community. Overall, we may observe that given the link between cultural spaces and engineering development in the cities, there is an under-evaluation of the contribution of the cultural identity. In reality, more cohesive and culturally linked vibrant communities are strongly supported by community identity, a diverse range of local interest groups, their economic activities and environmental management conditions responding to specific local needs through helping to make communities more culturally focused even when the population is shrinking. From a theoretical point of view, effects of shrinkage may conversely lead to the decline of urban growth factors, the dynamics of the nexus of environment-population-local economic development relationship result in different outcomes in different parts of the globe. This means that population decline in a region or country can either improve cultural assets management and related environmental conditions or degrade them all together.

\subsection{Examples of addressing the impact of shrinkage}

Spain as a country took a unique approach that involves participating in international frameworks, increasing the presence of the creative class as well as cultural tourism [10]. This emphasizes the need for global co-operation across regions with similar problems regarding shrinking population. It is also evidence of the importance of community artists in sustaining development beyond population shrinkage.

In Germany, the "Less is Future" project looks at shrinkage from a positive point of view. That shrinkage provides a new canvas to be creative with by making new space in the urban landscape. A good case example is the town of Dessau [11]. At first it was merged with another town, similar to the situation in the study area in Japan where Sakitsu Village and Imatomi Village were merged to create Tomitsu District. In Dessau, A state sponsored project suggested that "city islands," urban green zones and huge outdoor art could be part of the solution. Dessau's situation is the most similar case with the study area in Japan.

This project encompassed policy approaches for regional and inter-municipal cooperation as well as approached aiming at local culture, identity, economy and urbanistic interventions. This approach is evidence that the role of the government is very vital in 
regenerative approaches for shrinking regions. It also brings into play the role of local culture, identity and economy as well as interventions based on urban development principles. This includes community art spaces as support amenities for community development. This can be adapted to Lefebvre's theory of social reproduction.

In a normal situation, where population is growing, more emphasis in attaining sustainable development would be put on spatial practice to efficiently utilize scarce resources. But when population growth it is no longer a challenge but lack thereof, then existing or transforming local culture and identity becomes the centre of sustainable development as in the model employed by the "Less is Future" project.

Portugal as a country has also adopted a similar strategy, "Critical Area of Urban Regeneration and Renovation" that is focused on sustainability achieved through identity, creativity and renovation [10]. The development vectors for this project are: inhabitants the fundamental pillar of a living urban area; business - an opportunity to make the downtown district stand out in an urban area; commerce - the decisive factor in revitalizing the city; tourism, culture, leisure - innate forces of the city; public space - amenity support; and strategic action - necessary for success. This strategy has defined further the role of the different components of a region in its economic growth.

From the case examples, it can be deduced that in the regeneration of depopulated areas, sustaining the economy should be prioritized before increasing of the population if appropriate.

Japan has also had similar interventions over time. However, large scale sustainability has not been achieved over time and many rural communities now risk closing down. According to the Shrinking Regions Research Group, Japan presents an instructive case of a phenomenon experienced elsewhere but unlikely to be replicated exactly anywhere else. Both the new (Rural-Urban Migration) and old type (Ageing) of depopulation exists creating a double-negative demographic disequilibrium [7]. The presence of a society of gaps (kakusa shakai) between the metropolitan regions and the rest of rural Japan has now made it impossible to subordinate regional shrinkage to an unavoidable side story to national success. By 2016, over 60 rural cultural festivals were cancelled because the local communities shrunk more than the number of people it takes to hold the festival [12]. As much as the populous appears homogeneous, regional shrinkage issues are unique to specific regions and can therefore not be approached similarly. However, principles that have worked elsewhere and not the interventions themselves can be adapted to the unique situations of Japan's shrinking rural towns.

Looking at the case examples [7], [10], [11] and putting into consideration the Theory of Social production and construction of space [5], this study has prioritized sustained economic stability as alternative strategy. As cited by previous scholars in this area, revitalization will take place with or without human intervention... nature can revitalize a declined human settlement. If the focus is to regenerate the community with the community present then it is vital to focus on economic stability as a key pillar for regeneration. The success stories of regeneration in Europe utilized this approach first before encouraging new population to come in. In other words, if an area is economically stable and the current population too is stable for a sustained period then revitalization can become an option. Otherwise, an attempt for revitalization may suck out the little remaining population from the shrinking region.

The study area for this research is Tomitsu Waterfront in Amakusa, an Island city on the western end of Kumamoto Prefecture in Kyushu Island of Japan. The approach being advanced through my research is mapping of assets, identification of existing opportunities for strengthening local economic development, involvement of people in own activity and 
understanding of locally driven partnerships. Therefore, this study will add new insight to this kind of research in Japan. The study looks at community space and community activity, its management and the role it is playing and could play to sustain the local economy utilizing the concept adapted from Lefebvre's social construction theory and the case examples discussed in the previous section. Like the "Less is Future" project scenario, population regeneration is the main goal of this concept for the normal conditions of sustainable development to be achieved. However, sustainable development has to still be achieved to regenerate the area and stimulate conditions for population growth utilizing local culture and identity (community space and activity), socio economic production (economic sustainability) and spatial practice (community use of, management of and benefit from community assets).

\subsection{Study area and rationale}

From existing population and economic data [13], it is clear that not only is population decreasing (over 17\% loss in 10 years) but the number of households is decreasing as well. Also, it is evident that the household size is decreasing. This indicates that the number of property owners or tenants is also decreasing. This is a clear sign of the onset of urban decline. From previous data, both the population and household numbers have reduced between 2 census periods ( 5 years) Previously, Sakitsu area had a population of 598 with 272 households; Imatomi had a population of 423 with 203 households. Currently [14], the population of Tomitsu is 795 (489 in Sakitsu and 306 in Imatomi). The total household size is 380 (236 in Sakitsu and 144 in Imatomi). The total number of men is 357 (229 in Sakitsu and 128 in Imatomi) and the total number of women is 438 (260 in Sakitsu and 178 in Imatomi). Majority of the population is above 60 years while the minority is below 30 years of age.

This decline in population has culminated in closure of most elementary, junior high and high schools. The GDP from several industries has also been on the decline such as farming, fishing and grocery stores. The number of establishments has also been on the decline. The household per capita income has remained almost the same, however, the social security payments have increased and the overall household income is on the decline. This is evidence of an ageing population and shrinking households.

Besides the population decline statistics, Amakusa provides a unique study area. It is a historical landscape and after the Landscape law was enacted in 2004 [15], the whole of Amakusa City became a designated landscape planning area [16]. However, landscape and the environment have continually become the opportunity cost to safety, security and cost efficiency. These conditions are more aggravated by the population decline and budget constraint for Cultural Landscape preservation from government [15].

Previous literature cites association between use and management of community space and other community assets [2], [3]. There is also an important relationship between community identity and community space or assets. Community space is a structure of community identity [17]. Benefit from management of community assets has also been cited as a key factor to sustainable management [4]. Community management is essential for community development. Depopulation affects all these factors collectively.

With shrinking communities, community identity evolves faster can be easily neglected as an unavoidable opportunity cost for the macroeconomic development [7]. Without reinventing community identity, the notion of community assets blurs as the community gets smaller, use also diminishes and neglect arises. Since community identity has a role to play in use and management of community resources, this study is exploring the 
community assets relevant to the social and cultural identity of the residents of Tomitsu. The study aimed to find out what is regarded as community space and how it is related to community identity and what important activities take place within this community space.

Community spaces are supporting amenities for economic growth whereas community activities such as tourism, leisure and culture are innate forces of the city - drivers of the economy [10]. People do not see commercial places seated in their houses or in the car to a mall somewhere in a larger town. They see it on their way to and from or even inside the community space. Therefore, to ensure that local people support local business to grow the local economy, creative and innovative ways to encourage interactive and individual use of community space as well as management of this space should be developed through a consultative process or a participatory process. Also, as stated in the introduction, just as identity influences use of community space, the reverse is also true. Continuous use of community space creates a sense of belonging and creates root for residents to keep staying in a particular location. Therefore, community space and activity is not only essential for a stable economy but also for a stable population. Management should also include disaster and hazard prevention and recovery because these assets perform an important function of keeping in population.

Local tourism is a pre-cursor to foreign tourism. Foreign tourists visit destinations to enjoy nature and culture. So basically, it is to see the places and what people do in them. Therefore, community space and activity effectively managed and used by the community, will attract more foreign tourists. This also attracts investment and creates a basis for revitalization. There is need to manage important community activity in Tomitsu, especially the community festivals. There is need for innovative and creative approaches to keep traditional festivals in Tomitsu running so that they can keep shaping the identity of the people in this region and contributing positively to local business and investment.

\section{METHODS}

The main study area is Tomitsu in Kawaura Town of Amakusa City, Kumamoto Prefecture, and Kyushu Island, Japan. This study employed an incremental qualitative design adapted from the "Social Construction of Technology" [18]. The preliminary study was a type of "Snow Ball" to gather information on the important spaces, groups and activities in Tomitsu. This was accomplished through an Interactive Group Interview session.

The study area is Sakitsu and Imatomi. Sakitsu area has a population of 489 with 236 households; Imatomi has an estimated population of 306 with 144 households [14]. Sampling for the Interactive Group Interview was purposive and done according to Yamane, 1992; $\mathrm{n}=\mathrm{N} /\left(1+\mathrm{N}[\mathrm{e}]^{2}\right)$ Where $\mathbf{n}=$ sample size, $\mathbf{N}=$ total population and $\mathbf{e}=$ acceptable sampling error. The acceptable sample for the study at an acceptable error of $3 \%$ is 11 . However, for the preliminary study, the real obtained sample was $9(81.8 \%)$.

This was followed by observations of these spaces and discussions with these groups as well as participation and observation of these activities. According to Lefebvre, social space is hierarchical. Not all social space has the same attractiveness to members of a society and there are spaces more usually inclined to individual than group activities and vice versa given the time and period.

Given this, this study identified in order of hierarchy what are considered important public spaces for individual use and social space for group gatherings. As this was a local study, these were related to geography and ecology (location), economy and commerce (livelihood), socio-cultural (culture and religion) and socio-political (Association) dynamics of space. Relationships and transformations were established in close comparison 
to Lefebvre's Social Production and Construction Theory that analyses space in terms of its nature (form), social life (rhythm and genesis) and spatial practice (management) [5].

Also, systems and processes of the important community activities identified were sought out in the discussion including relevant changes and other information. As the basic sample was averagely 67 years old, the "Snow Ball" could not catch information about children and the youth therefore a further inquiry was made during the focus group discussion. This paper integrates the preliminary findings from the "Snow Ball" (Presented at HABITAT III Programme Parallel Workshop) and the focused group discussion and observation findings to elaborate important community (social) space and activity and their management, their current contribution to community development according to the residents of Tomitsu and their potential future contribution according to the author.

\section{RESULTS AND DISCUSSION}

Like the REGEN project this study looks at potential of the area but not from the socioeconomic production point of view [9] but from spatial production point of view.

The population of Tomitsu is mainly made up of the aged [14]. This dynamic seems harmless but it determines which spaces are available, used and maintained. Most schools are closed because the number of children could not sustain the existence of the schools and the children had to attend school in a neighbouring village. There are a limited number of children facilities and fields are mostly used for golf. Children either have to be content staying at home playing video games or play in the closed school's field while it still has not been developed into something else. According to the responses from the group discussion there are also no appropriate places for young people to meet up. Though young people are a minority population they are very important because natural population growth of the area is dependent on them. They are therefore a very delicate population bracket because they are most likely to move out of the District and having no amenity they can hold onto it is highly probable for them to leave other than stay; and they do leave, causing gaps in community management. Another special group is the children because though it may take them a bit more time, if there is nothing to hold onto when they become youth, then the same narrative will apply.

\subsection{The hierarchy of community space}

Community space consists of space for individual use and space for group activities. During special occasions, these spaces become venues for community activity. Since individual use of space is subjective, then a hierarchy of the importance ascribed by different individuals can be created for this space [5]. The table below illustrates this hierarchy constructed from the field data.

Except for natural spaces that were built on especially along the coast, most of these spaces still exist with their uniqueness. Each of these spaces has unique attractions in their nature and the types of activities that take place in them daily. The spaces marked in yellow are spaces outside Tomitsu. It is evident that young people and workers both now and in the past three decades have preferred to spend time and enjoy social activities outside Tomitsu. The spaces for group activity include the School grounds, the street, Grand Golf Park, the Bench outside the church, the dockyard behind the church and the bench outside the post office.

The spaces marked green in the Table 1 are no longer in usual use but still maintain their form and nature and have the potential for recreation or modernization of children's 
Table 1: Hierarchy of community space.

\begin{tabular}{|c|c|c|c|c|}
\hline \multirow{12}{*}{ Current } & AGED & & & \\
\hline & The sea and Beach & & & \\
\hline & Street & & & \\
\hline & Shrine & & & \\
\hline & Farmlands & & & \\
\hline & Church & & & \\
\hline & Community Center & & & \\
\hline & Guidance Center & Hierarchy of Communit & Space & \\
\hline & $\begin{array}{l}\text { Cherry } \\
\text { Park }\end{array}$ & YOUTH/WORKERS & CHILDREN & \\
\hline & Iwashita House & Work (City) & $\begin{array}{l}\text { School } \\
\text { Playground }\end{array}$ & \\
\hline & Yura Bridge & Gaming Station (City) & Street & \\
\hline & Buddha Statue & $\begin{array}{lll}\text { Other Social } & \text { Spaces } \\
\text { (City) }\end{array}$ & Home & \\
\hline & & School & $\begin{array}{l}\text { School } \\
\text { Playground }\end{array}$ & \\
\hline & & Sea and Beach & Guard Station & \\
\hline & Future? & Gaming Station (City) & Church & Dost \\
\hline & Future? & Work (City) & River & Past \\
\hline & & & Shrine & \\
\hline & & & Sea and Beach & \\
\hline & & & Mountain & \\
\hline
\end{tabular}

activities that used to take place there like fake sword fighting and walking on stilts. They just require some modification in the form to appeal to children and the youth. A good example is the mountain on which the Suwa Shrine is located that provides a unique interface with nature and a near modern design.

\subsection{Classification of community space}

Community social space above was classified into three categories: natural space (the sea, Kodaka Beach, the mountains, river and fields); art space [2] (Cherry blossoms park, guidance center, community center, school, shrine and church); and, civic Space [19]. civic space in Tomitsu can be classified under public infrastructure (street and sidewalk, Grand Golf Park, Yura Bridge, pier and dockyard, community center, guidance center and school); religious and cultural monuments (shrine, church, Buddha statue and church); and, commercial space (post office and Hashimoto parlour).

\subsection{The management of community space}

Community members manage community space in Tomitsu in different ways. The managed spaces are all in the list for important social spaces that include: the church, the levees at the fishermen's pier, and the orange orchard which are management by individual members of the community; the public street, the church street and sidewalk which are cleaned and decorated twice a year by the Volunteer Association; the cherry blossoms park which is taken care of daily by individual community members and cleared of weeds twice a year by the Volunteer Association; and, the shrine which is cleaned once 
or twice a month by the Aged Members Club and twice a year by the Volunteer Association. This justifies the concept of this study that there is indeed a relationship between use and management of community space and when use stops, so does management. The spaces that were marked in green are not on this list because they are no longer in use. Though children still play in the closed school grounds, these grounds are not managed in any way by the members of the community because the school's main use was stopped. Another important space not in the list but managed is Kumamoto University's Tomitsu lab with provides an academic and cultural interface between the local community in Tomitsu and the university.

\subsection{Case example of community space (the Suwa Shrine)}

The shrine is built in a small fishing village on Shimoshima Island in Amakusa (which is part of Kumamoto prefecture). The shrine's torii (archway) is inscribed with the date 1685, and it remains standing in the spot where it was first erected. During the ban on Christianity in Japan, many of the people living in Sakitsu village were Hidden Christians. The village's population was strictly monitored, and so the Hidden Christians joined Sakitsu Suwa shrine as a way to avoid being discovered. The shrine appears on maps from the Edo period. It has been loved by people in Sakitsu since it was first built [20].

Currently the Sakitsu Suwa Shrine has sanitary facilities, handicap facilities, a parking space and a newly constructed park space. It is constructed on a hill with 524 stairs up to the hilltop agora. The shrine is cleaned by the aged members club of the community, improved by the city government and its main activities (The Suwataisha Festival and prayer and meditation) are organized by all the members of the community. The Suwa shrine has the potential to be an architectural and anthropological study site as well a venue for community social and educational events. This is because it provides a variety of multipurpose spaces within it such as the hill top agora, the parking space, the new park space and the flight of stairs. The hill top agora also has the potential to be the best evacuation site in case of seaward disaster.

Therefore, the shrine facility is a vital part of this community as a support amenity for development. Beloved by all members of Tomitsu, it is a symbol of the community's identity. Also, with local shops along the side walk at its base and the high climb, it is well placed to encourage local spending which is good for the local economy. Using other community spaces also requires a commute mostly on foot so they can all play a more active role in maintaining the economy of Tomitsu District, reducing outmigration, promoting local business and attracting tourists and mostly maintaining the satisfaction of the residents as they keep living there and welcoming visitors and new settlers where appropriate.

\subsection{Community activity}

As stated earlier, community activity is the innate force that drives regeneration and renovation. From the preliminary study, three major community festivals were identified in Tomitsu District. Traditional festivals identified were the Sakitsu Suwataisha Festival, and Imatomi Jyugoshagu Festival. The Minato Festival is the only modern festival commissioned 28 years ago by the prefectural government.

\subsubsection{Sakitsu Suwataisha festival}

The festival is the Sakitsu Suwa Shrine's Festival. It is held annually on $23^{\text {rd }}$ November. It is a religious festival. This is purely a local festival organised by the local community to 
pray for good health and bounty/haul in fishing. This festival is a symbol of the community's solidarity power. It is sustained to maintain this sense of community and unity and if it were to fail this would be lost. The materials and labour required for this festival to hold are availed by cooperation of all community members.

\subsubsection{Sakitsu Suwataisha festival systems and processes}

The community system for organising this festival is managed by SOUDAI. The membership of SOUDAI is open to any community members willing to take up the leadership role. These are 12 representatives of the civic parishes that make up Sakitsu Village (Mukae, Shimomachi, Nakamachi and Funatsu). The SOUDAI basically do capacity and resource mobilisation as well as organize the logistics for the Suwataisha Festival. They ensure that each civic parish cooperates to ensure the festival is a success. They meet once every month from September to November. On the festival day, they put up the flag for the festival, do the cleaning and perform the Shinto straw festoon decoration.

With a budget of about 1,000,000Yen, three areas; Nakamachi, Shimomachi and Funatsu make financial contributions to the festival. Each household contributes $3000 \mathrm{Yen}$ for the festival and the members of SOUDAI-UJIKO SOUDAI have to collect this fund which is a tedious process. Mukae contributes to the festival by material labour. They are involved in the making of Shinto straw festoon (SHIME NAWA) (A sacred straw festoon in Shinto Rope used to cordon off consecrated areas or as a talisman against evil). Though festival stalls (TEKIYA) are not so many for this this festival, there are some. Shop owners interested in having a festival stall at the festival must pay branch charges of $3000 \mathrm{Yen}$ before the festival as they intend to profit from the festival participants. The branch fee goes to holding the next festival while the local business owner benefits by getting access to the market offered by festival participants. Therefore, local business and local festivals are co-dependent.

The main challenge faced by the festival is collection of funds which is a very tedious process and also very difficult, more so because the number of households keeps reducing. Another challenge is succession. Traditionally, succession for the roles in the festival such as performing rites, making offerings and prayers, carrying the festival artefacts; is allocated by family social standings and since many young people move out of Tomitsu for work or study, this leaves gaps in succession and the aged have to keep performing these festival rites for as long as they can. Activities like carrying the small shrine (OMIKOSHI) can be delegated and annually, Tomitsu Laboratory members volunteer for this role in the festival as the OMIKOSHI is very heavy and the community requires some assistance with it.

In order to ensure continuity of the festival, the SOUDAI recommended for an alternate solution for the issue of the successor. Some traditions about the festivals have changed over the years to accommodate the population loss; for instance, the festival drum (DAIKO) that was mainly played by boys is also played by girls now because the population of children in low. As the study has to finally develop a management strategy with the community, the issue of succession is very essential.

\subsubsection{Imatomi Jyugoshagu festival}

This festival is organised for good health and bountiful harvest from the fields. Like the Suwataisha Festival it is also a religious festival and is also organized by a traditional system of SOUDAI. This festival faces similar challenges due to population loss but unlike the Suwataisha Festival, university students do not volunteer. However, support to hold the 
festival is received from the neighbouring Village of Oe. Therefore, just like Sakitsu Village, it is vital for Imatomi Village to ensure the continuity of this festival.

\subsubsection{The Minato festival}

Compared to the two festivals above this one is the youngest. It is only 28 years old and is held every first Saturday of August. This festival was commissioned by the prefectural government to invigorate/revitalise the community and support local business in Amakusa City. It mainly consists watching fireworks, and the Sakitsu Church light up and having good time. Before the festival, the committee meets one a month from May to August to plan and prepare. After the festival, the committee meets to evaluate the previous festival and set the stage for the following festival. The committee has an open membership policy. Just as the other two festivals, community members also contribute money for the organization of this festival. The committee is in charge of collecting these contributions as well as the branch fee for the TAKEYA. They also invite local business branches and promote the festival inside Tomitsu and in surrounding areas.

When the festival began, the city government gave subsidy of 2,000,000 3,000,000Yen which is almost the entire cost of the festival $(3,000,000$ Yen) but over time the funding has reduced to $1,000,000$ Yen. This can be attributed to reduction of city revenue over time especially due to shrinkage. The current organising committee for this festival is called the Planning Committee for Sakitsu Minato Festival. From the preliminary studies, they are the third group to manage the logistics of this festival since its inception. Before them was the Chamber of Commerce and Industry and before was the Fishermen's association youth group. Local industry and businesses as well as the local fishing industry have also been facing decline because of the decline in population. The change in management can be indirectly ascribed to shrinkage as well. To cover up the rest of the cost the committee accepts contributions from community members but also has to solicit sponsors. Another fundraising technique is payment of branch fees by TAKEYA shop owners which is 3000 Yen per stall. However, for this festival the shop owners are not from Tomitsu but from the rest of Amakusa city. The local fireworks company in Amakusa City provides the fireworks at an affordable price.

Though TAKEYA are not locally owned local businesses in Sakitsu benefit by being open during the festival. About 3000 people attend this festival every year and this is good business for local shop owners. This shows the co-dependence between community activity and local business and commerce. The main challenge for this festival is also fundraising. Since this is a high tourist event in Tomitsu, it is necessary for the community to take full advantage of it creatively so that the festival sustains itself and there is no longer need for fund raising even for the other festivals facing this problem.

\section{COMMUNITY SPACE, ACTIVITY, MANAGEMENT AND COMMUNITY DEVELOPMENT IN TOMITSU WATERFRONT}

From the information obtained during the preliminary study and the group discussion and well as observations; though the conditions in Tomitsu District are similar to those in Dessau in Germany; which is similar the study concept [11], the components of the community management process in Tomitsu district bears more similarity to the Portuguese approach [10]. The components of the development process in the case of Tomitsu District are community space, community socio-cultural activity, community socio-economic activity, Community management, succession and regeneration, and economic stability. These consists the aspects of Lefebvre's theory [5] in a more simplified and defragmented way. 
Community socioeconomic activity and sociocultural activity both take place within community space in Tomitsu District. Some significant spaces are: the seafront, the street and sidewalk, the fields, Sakitsu Suwa Shrine and Imatomi Shrine. These community spaces have been identified as important symbols of community identity and rank highly in the hierarchy of community space. In these spaces, the three important community festivals take place. These are the major socio-cultural activities. Community socio-economic activity also takes place within the above community spaces. Community space hosts community activities which encourage tourism and leisure: these are the innate drivers of the local economy. This proves that community space is an amenity support for community activity.

Community management or spatial practice is the system that ensures harmony and continuity of community space and its associated activities. In Tomitsu it is done at individual level, or by Association. Effective management is the key to a sustainable economy. Succession within the community is necessary for sustained spatial practice and has been voiced by the study respondents as the main challenge that needs effective solution. It is therefore at the center of the community management system as the aspect that influences use and management of community space and activity. The linkage of these components is the model of community management in Tomitsu and is essential especially in the goal to achieve economic stability in Tomitsu and appropriately manage the shrinkage process.

\section{CONCLUSION}

From the preliminary and group discussion findings as well as real time observation of community space in Tomitsu, it is clear that the space is a social product. This space use, management and benefits are a result of community identity but changes in these aspects can also mean change in the identity structure of a region. It is also clear that community activity and economic development are co-dependent. For effective sustainable development of the Tomitsu waterfront or any other community undergoing redevelopment, the best course of action is to appraise the available community assets, before building new ones and figure out how to adapt them in order to drive community development in the positive direction. Though for academic purposes, this study aims to share its result with the authorities and residents of Tomitsu so that it can contribute a little to Tomitsu's future development.

\section{ACKNOWLEDGEMENTS}

The author gratefully acknowledges the guidance of Ass Prof. Naoto Tanaka as well as the valuable input and assistance of Mr. Tare Kazuki in Data collection, translation and mapping. I would also like to acknowledge the cooperation and assistance of the residents of Tomitsu District, especially the members of the festival organization committees for providing the data presented in this paper.

\section{REFERENCES}

[1] Kido, E.M., New urban and landscape design of the Nihonbashi district in Tokyo, 2008.

[2] Groadach, C., Art spaces, public space, and the link to community development. Community Development Journal, 2009. DOI: 10.1093/cdj/bsp018.

[3] Borrup, T., The creative community builder's handbook: how to transform communities using local assets, art and culture, Fieldstone Alliance, 2006. 
[4] Award, U., Creating a rich waterfront environment: the challenge of Toyama Prefecture. Irrigation, Engineering and Rural Planning, (30), 1996.

[5] Lefebvre, H., The Production of Space, Translated by Daniel Nicholson-Smith. Basil Blackwell Ltd, 1984.

[6] United Nations Conference on Housing and Sustainable Urban Development (Habitat III) Quito, 17-20 October 2016. Item 10 of the provisional agenda**, Adoption of the final outcome of the Conference.

[7] Matanle, P. \& Rousch, A., Japan's Shrinking Regions in the 21st Century: Contemporary Responses to Depopulation and Socioeconomic Decline, Cambridge University Press, 2012.

[8] Edgington, D.W., Japan's Shrinking Regions in the 21st Century: Contemporary Responses to Depopulation and Socioeconomic Decline. Regional Studies, 46(9), pp. 1275-1276, 2012. DOI: 10.1080/00343404.2012.722369

[9] Lulea Institute of Technology: Regeneration of European Shrinking Regions, Online. http://www.ltu.se/research/subjects/Arkitektur/Forskningsprojekt/RegenerationEuropean-Shrinking-Regions-1.159608?1=en

[10] Martinez-Fernandez, C., Kubo, N., Noya, A., Weyman, T., Demographic Change and Local Development: Shrinkage, Regeneration and Social Dynamics, OECD/LEED, 2012.

[11] When less is more: eastern German project provides hope for shrinking cities, Online. http://www.spiegel.de/international/germany/when-less-is-more-easterngerman-project-provides-hope-for-shrinking-cities-a-688152.html

[12] The Japan Times: Sixty traditional folk events halted in rural Japan due to depopulation, aging, Online. http://www.japantimes.co.jp/news/2017/01/04/national/ rural-japan-halted-60-traditional-folk-events-due-depopulation-aging/\#.WKO5nN SLSXI

[13] Amakusa City Website: 2015 Population Data http://www.city.amakusa. kumamoto.jp/

[14] Japan in numbers: a portal site for Japanese Government Statistics, Online. http://www.e-stat.go.jp/SG1/estat/GL08020103.do?_toGL08020103_\&tclassID=00 $0001082885 \&$ cycleCode $=0 \&$ requestSender $=$ estat

[15] Kakiuchi, E., Cultural Heritage Protection System in Japan National Graduate Institute for Policy Studies. GRIPS Discussion Paper, 14(10), 2014,

[16] Tanaka, N., Diversity and Dynamism of participation in Japanese Cultural Landscape preservation, Centre for Policy Studies, Kumamoto University.

[17] Wilson, S.A., Identity, Culture and the politics of community development, Cambridge Scholars Publishing, 2015.

[18] Pinch, T. \& Bijker, W., The social construction of facts and artifacts: Or how the sociology of science and the sociology of technology might benefit each other. In The social construction of technological systems: New directions in the sociology and history of technology, W. Bijker, T. Hughes \& T. Pinch (eds), pp. 17-50, Cambridge, MA: MIT Press, 1987.

[19] Balassiano, K., \& Maldonado, M.M. Civic spaces in rural new gateway communities. Community Development Journal, 2014, 49(2), pp. 262-279, 2013.

DOI: https://doi.org/10.1093/cdj/bst029.

[20] Website of Churches and Christian History and Cultural Heritage of Nagasaki, Online. http://oratio.jp/p_resource/sakitsusuwajinja?type=r_en 